\title{
SISTEMAS CONSTRUTIVOS COM USO DE RESÍDUOS: UMA ALTERNATIVA PARA REDUZIR O CUSTO DA HABITAÇÃO POPULAR
}

\author{
MARIA ARIDENISE MACENA MAIA ${ }^{1}$ \\ EULER SOBREIRA MUNIZ \\ MARIA DO CARMO DUARTE FREITAS ${ }^{3}$ \\ NORICKAGURJÃO NORONHA DE MELO"
}

MAIA, M.A.M.; MUNIZ, E.S.; FREITAS, M.C.D.; MELO, N.G.N. de. Sistemas construtivos com uso de resíduos: uma alternativa para reduzir o custo da habitação popular. Semina: Ci. Exatas/Tecnológicas, Londrina, v. 16, n. 4, p. 569-573, dez. 1995.

RESUMO: Este trabalho é resultante de uma pesquisa bibliográfica que visa, sobretudo, verificar a possibilidade do uso de materiais alternativos na elaboração de um sistema construtivo que minimize o custo da habitação popular sem comprometimento das dimensões e/ou número dos ambientes da casa. Desta maneira, fez-se um levantamento dos sistemas construtivos existentes e dos resíduos que já foram usados em construção. Desse estudo percebeu-se que, nos sistemas construtivos existentes há uma predominância dos derivados de cimento e madeira. Estes materiais são inadequados em termos de nordeste: o primeiro pelo desconforto térmico que o mesmo proporciona e pelo preço considerável que apresenta, e, a carência do segundo inviabiliza seu emprego na região. Por fim, a continuidade deste trabalho será obtida pela elaboração de um sistema construtivo à base de argila e resíduos tais como: restos de tecidos da indústria de confecção, fibras vegetais e garrafas plásticas descartáveis.

PALAVRAS CHAVE: Sistema construtivo; resíduo; conforto térmico; habitação popular.

\section{INTRODUÇÃO}

A questão da habitação popular brasileira é um tema que se agrava cada vez mais. No Brasil, o déficit gira em tomo de 12 milhões e em Fortaleza já chega a 150 mil.

$\mathrm{Na}$ década passada, as casas dos conjuntos habitacionais possuíam de um até três quartos, além de sala, cozinha e banheiro. Entretanto, a alternativa encontrada para reduzir os custos destas residências usada pelos empresários e pelo Sistema Financeiro de Habitação para aumentar o número de moradias executadas, foi a execução de habitações com apenas sala, cozinha e banheiro. Um exemplo deste comportamento foi mostrado pela imprensa em casas embrião financiadas pelo PEP (Plano Empresarial Popular), e PROHAP (Programa de Habitação Popular), onde além do número de dependências ser inferior ao mínimo necessário às atividades diárias, as áreas dos ambientes eram extremamente reduzidas.

Embora, tenham sido desenvolvidos e muitas vezes até industrializados, alguns sistemas construtivos que barateiam o custo da casa para a população de baixa renda, nenhum deles teve a preocupação em reutilizar os resíduos sólidos como alternativa.

Este artigo é resultante de uma pesquisa bibliográfica que visa sobretudo, verificar a possibilidade de uso de materiais alternativos na elaboração de um sistema construtivo que minimize o custo da casa popular, evitando assim um comprometimento das áreas e/ou número de ambientes mínimo da edificação.

\section{A QUESTÃO DOS RESÍDUOS}

Há quem faça certa confusão entre os termos reduzir, reutilizar e reciclar; por isso, será feita a distinção entre eles.

Reduzir significa evitar de todas as maneiras possíveis e imagináveis à formação de determinado resíduo durante o desenvolvimento de certa atividade.

Se, depois da tentativa de redução de resíduos, ainda existir material sólido, deve-se reutilizar o mesmo, ou seja, dar um uso diferente ao mesmo.

1. Eng. Civil, Msc, Pesquisadora do Núcleo de Pesquisas Tecnológica e Professora da UNIFOR - Rua Dermóstenes Carvalho, $660 / 302$ -

Monte Castelo - Fortaleza-CE - 60320 440 E-mail denise@feq.unifor.br - Fax (085) 2265690.

2. Arquiteto, Pesquisador do Núcleo de Pesquisas Tecnológicas e Professor da UNIFOR.

3. Aluna de Engenharia Civil e Estagiária do Núcleo de Pesquisas Tecnológicas.

4. Aluna de Engenharia Civil e Estagiária do Núcleo de Pesquisas Tecnológicas.

Semina Ci. Exatas/Tecn.. v. 16. n 4, p, 569-573 
Por exemplo, se existe um equipamento denominado masseira ou moinho que tritura os seguintes resíduos:

a) pedaços de tijolos resultantes dos rasgos executados na alvenaria para colocação de tubulação;

b) pedaços de tijolos oriundos do transporte e manuseio em obra na execução de alvenaria e

c) argamassas recolhidas no piso, oriundas de chapisco, emboço e reboco;

transformando os mesmos em materiai para produção de argamassa, então se está reciclando o resíduo. Para tal, deve-se primeiramente tentar reduzir, para posteriormente reciclare, porfim, reutilizar este restante na obra.

Portanto, neste caso especifico, antes de decidir por reciclar o material, deve ser realizada uma análise da possibilidade de redução da geração desse material da seguinte forma:

a) Aplicar o chapisco com rolo, evitando assim a queda do material como ocorre no método convencional;

b) Criar sistemas de controle para compra de tijolos, inclusive definindo requisitos e critérios, para evitar quebras excessivas devido ã fragilidade do material;

c) Usar tijolos pré-sulcados, para evitar os rasgos nas alvenarias.

Mas, caso uma dessas alternativas não possa ser usada deve-se, por exemplo, buscar o reaproveitamento do material para enchimento de piso, mesmo num momento em que existe uma concentração de esforços visano ã execução do contrapiso zero.

A questão do resíduo usado em construção merece a seguinte reflexão: enquanto algumas indústrias, como a eletrônica, por exemplo, è medida em que evolui, se moderniza e passa a consumir menos material na fabricação de seus produtos, Na construção civil, isso não ocorre. Uma prova disso é obtida comparando-se a quantidade de materiai usado na fabricação do primeiro computador, com a necessária atual.

$\mathrm{Na}$ construção civil, ocorre algo diferente. O consumo de material necessário é função do espaço edificado, fazendo com que o uso de material não seja reduzido ã medida que se moderniza a construção.

Uma prova disso pode ser obtida se compararmos o consumo de materiai por metro quadrado de uma construção convencional com a construção racionalizada. Na primeira, o consumo varia de $1,5 \mathrm{t} / \mathrm{m}^{2}$ a $2,0 \mathrm{t} / \mathrm{m}^{2}$, e na segunda esse valor passa para $1,2 \mathrm{t} /$ $\mathrm{m}^{2}$.
Quando se trata de resíduos, dois aspectos são relevantes. O primeiro consiste em avaliar a viabilidade do uso de determinado resíduo, ou seja, se existe em quantidades suficientes para emprego na construção civil. O segundo, seria fazer uma pauta em cima dos danos causados por este material. De acordo com CINCOTTO (1988), a utilização do resíduo na construção civil passa por um critério de viabilidade, envolvendo basicamente a localização, a abundância e a nocividade do mesmo. Em se tratando dos males causados pelos resíduos, tem-se:
a) Comprometimento estético da paisagem
b) Riscos à saúde púbiica
c) Ocupação do espaço
d) Custo do recolhimento-processamento
e) Degradação dos recursos naturais.

Dando continuidade aos motivos que levam ã busca de usos específicos para determinados resíduos, chegamos à ISO 14000. Trata-se de uma norma que está em elaboração na Europa e que visa suprir algumas deficiências da série ISO 9000 no que concerne aos aspectos ambientais. Portanto, num futuro não muito distante, existirá uma fiscalização mais rigorosa em termos de geração de resíduos por parte da empresa, levando assim ã necessidade de outras alternativas para reutilização desses materiais.

\section{O USO DOS RESÍDUOS PARA CONSTRUÇÃO DA HABITAÇÃO}

Alguns resíduos de mineração são usados para construção de rodovias em países como: Bélgica, Canadá, Dinamarca, Finlândia, França, Alemanha, Itália, Holanda, Espanha, Suíça, Reino Unido e EUA (CINCOTTO, 1988).

Além disso, são empregados resíduos e subprodutos metalúrgicos, industriais, municipais, agrícolas e florestais para fabricação de blocos, painéis, chapas onduladas e outros tantos produtos que são usados na construção.

Embora exista na Europa e nos EUA um uso de resíduos na construção, no Brasil, isso ainda não ocorre com tanta freqüência, sobretudo no que diz respeito ã elaboração de um sistema construtivo para habitação popular.

Fazendo-se um levantamento a respeito de algumas utilizações de resíduos em construção em nível nacional, tem-se:

1. Emprego da casca de banana na fabricação de tijolos (OLIVEIRA, 1994); 
2. A utilização de resíduos da indústria de papel na produção de materiais para vedação tais como: painéis divisórios, placas para forro, blocos e tijolos (NOLASCO et al. (1993).

3. Confecção de argamassa a partir da lama de caí com cinzas de eucalipto e introdução de fibras da casca de côco. Este trabalho é parcial, e a idéia é confeccionar painéis com este material (SILVA (I) et al., 1993).

4. Uso da casca de arroz tanto para confecção de tijolos (FONSECA, 1993), como para obtenção de aglomerantes aitemativos pela junção da cinza de casca de arroz com o cimento portland (GUEDERT, 1989).

5. Confecção de argamassa a partir da trituração dos tijolos quebrados, da argamassa endurecida por não ser usada e da recolhida do piso resultante da aplicação de revestimento e/ou execução de alvenaria (MA1A, 1993).

6. Tijolo cerâmico com introdução de lodos industriais. (COSTA, 1986).

\section{OS SISTEMAS CONSTRUTIVOS EXISTENTES}

O sistema construtivo mais conhecido, denominado convencional, é aquele construído de alvenaria de blocos cerâmicos furados, maciços e blocos de cimento.

Além deste, existem vários outros que, na grande maioria das vezes, são concebidos a partir da madeira ou de placas pré-moldadas de concreto.

Recentemente, foi publicada na Revista $A$ Construção Norte/Nordeste uma reportagem sobre a Vila Tecnológica. Trata-se de um projeto do governo itamar Franco denominado de PROTECH (Programa de Difusão de Tecnologia para Construção de Habitação de Baixo Custo) que reúne sistemas industrializados em caráter experimental numa vila tecnológica.

Embora a primeira vila tenha sido instalada em Curitiba-PR, foram assinados protocolos de execução em Ribeirão Preto-SP, Juiz de Fora -MG, Brasília-DF, Cuiabá-MT, Contagem-MG e Bauru-SP. O que não fica claro na matéria é qual foi o critério de escolha destes locais.

O principal objetivo deste programa é mobilizar a comunidade técnica para avaliação dos sistemas construtivos industrializados.

A Vila Tecnológica de Curitiba compreende 120 unidades habitacionais, das quais 100 são financiadas para avaliação durante uso e 20 para a Rua das Tecnologias.

A Rua das Tecnologias é uma espécie de showroom de sistemas construtivos em que são apresentadas alternativas de construção popular procedentes de vários estados, conforme mostra o Quadro 1.
Quadro 1. № de sistemas construtivos de cada Estado

ESTADO

$N^{\circ}$ DE SISTEMAS

CONSTRUTIVOS

$\begin{array}{ll}\text { RS } & 03 \\ \text { PR } & 07 \\ \text { MG } & 02 \\ \text { MT } & 01 \\ \text { SP } & 03 \\ \text { DF } & 01 \\ \text { PA } & 01 \\ \text { TOTAL } & 18\end{array}$

Em se tratando dos materiais utilizados, existe uma predominância de produtos derivados de cimento e de madeiras conforme mostra o Quadro 2.

Quadro 2. Número de sistemas construtivos de cada material

\section{MATERIAL EMPREGADO}

Painel concreto

Madeira

Tijolos do cimento

Argamassa armada

Concreto celular

Bjoco concreto

Bloco intertravado

TOTAL

\section{$N^{\circ}$ DE SISTEMAS CONSTRUTIVOS}

08

05

01

01

01

o1

01

18
No caso do nordeste, estes materiais que predominam na execução dos sistemas construtivos industrializados não parecem adequados por dois motivos básicos; a madeira, pela carência do material na região e os painéis de concreto, tanto pelo preço considerável do cimento, quanto pelo desconforto térmico provocado por este tipo de material. 
Ainda sobre os diversos tipos de sistemas construtivos, pode-se citar o trabalho que trata do estabelecimento de uma metodologia para seleção de sistemas construtivos inovadores realizado pelo CTE SILVA (II) (1993), envolvendo 16 tipos diferentes, conforme mostra o Quadro 3.

Quadro 3. Sistemas construtivos estudados pelo CTE

\section{EMPRESA SISTEMA CONSTRUTIVO}

1

2

3

4

5

6

7

8

9

10

11

12

13

14

15

16
Painéis pré-fabricados de concreto.

Alvenaria de blocos cerâmicos.

Estrutura e cobertura metálica c/alv. bloco cone.

Pilaretes e placas pré-fabricadas de concreto.

Paredes de concreto leve moldadas "In loco ".

Paredes de concreto celular moldadas "in loco ".

Placas pré-fabricadas de concreto.

Painéis de argamassa armada.

Pilaretes e placas pré-fabricadas de concreto.

Painéis sanduíche de madeira e argamassa.

Painéis alveolares pré-moldados de concreto.

Alvenaria de blocos de concreto.

Painéis alveolares de concreto protendido.

Paredes monolíticas de concreto moldado" in loco".

Painéis pré-fabricados de concreto e blocos cerâmicos.

Painéis alveolares pré-fabricados de concreto.
A partir do Quadro 3, percebe-se que houve praticamente uma unanimidade no emprego do concreto para execução dos sistemas construtivos, ou seja, com exceção do convencional e do de Painéis sanduíche e argamassa, os demais são todos oriundos do concreto.

Existem ainda algumas tecnologias que não chegaram a ser industrializadas, mas que são, de uma certa forma, de conhecimento popular, tais como:

a) Tijolo solo cal;

b) Paredes monolíticas de soio cimento; lados e

c) Blocos de cimento com encaixe nos quatro

d) Painéis cerâmicos pré-moldados.

\section{CONSIDERAÇÕES FINAIS}

Como foi colocado no início, este trabalho está baseado apenas na pesquisa bibliográfica que servirá de base para a prática experimental de um processo construtivo a partir do reaproveitamento de resíduos locais.

Desta maneira, fez-se um levantamento dos tipos de resíduos que já foram empregados na construção civil, bem como dos tipos de materiais ou componentes de construção originados.

Além disso, procurou-se buscar os sistemas construtivos executados no país, tanto industrializados como aqueles desenvolvidos em centros de pesquisas e/ou universidades, mas que ainda não foram fabricados em série.

Do confronto destas duas informações percebe-se que os resíduos foram usados na construção, na maioria das vezes como material de construção e não como um sistema construtivo industrializado.

Em se tratando dos sistemas industrializados existentes, tem-se, nos derivados de cimento e madeira, uma maioria expressiva. Como foi comentado no texto, estes materiais não são recomendados como principais elementos das habitações na região nordeste, pelo desconforto térmico ocasionado pelo uso excessivo do primeiro e pela pouca disponibilidade do segundo no local.

Por isso, sugere-se um sistema construtivo à base de argila e fibras de resíduos locais tais como: sobras de tecidos da indústria de confecção, plástico de copos e garrafas descartáveis dentre outros.

Acredita-se que desta maneira estaria sendo fabricado um material que proporcionaria um certo conforto térmico, uma minimização do efeito de retração por secagem além de um custo reduzido, uma vez que as fibras seriam obtidas dos resíduos. 
MAIA.M.A.M.; MUNIZ, E.S.; FREITAS, M.C.D.; MELO, N.G.N.de. Constructive systems with the use of not conventional materiais: an alternative for reducing the cost of popular habitation. Semina: Ci. Exatas/Tecnológicas, Londrina, v. 16 , n. 4, p. 569-573, Dec. 1995.

ABSTRACT: This articie is a result of a bibliography reserch. It intends to verify the possibility of using not conventional materiais for building up low cost houses, mantainig usual sizes and prices that poor people can pay. By means of this study it was possible to notice that, in the constructive systems used so far, there is a predominance of cement and wood which are not considered proper for use in the northeast of Brazil, in terms of thermal discomfort, price and lack of wood in this region. The purpose of this research is to discover a building sistem involving clay and trash as a result of clothing industries, vegetable fibers and plastic bottles.

KEY-WORDS: Construct system; clothing's; termical confortable; low coast houses.

\section{REFERÊNCIAS BIBLIOGRÁFICAS}

CINCOTTO, Maria Alba. Utilizaçāo dos subprodutos e Residuos na Indústria da Construçäo Civil. In: Tecnologia das Edificaçöes. São Paulo, PINI, 1988.

DA COSTA, Hèlio Ramos; FERRERA, Gláudia Fróes. Introdução de Lodos industriais contendo metais pesados em tijolos de ceramica. In: Engenharia Sanitaria, vol. $25, \pi^{\circ} 3$, jul/set 86 , Rio de Janeiro.

DE OLIVEIRA, Marcos. O que é que a bànana tem? Residuos de bananeíra são usados como material de construçāo e para fabricação de môveis. In: Globo Ciència, maio, 1994.

GAYER, André et alli. Sistema Construtivo para habitaçāo popular utilizando resíduos agricolas. In: Encontro Nacional de Tecrologia do Ambiente. Construído: Avanços em tecnologia gestäo da produção de edificaçōes. Sāo Paulo, 1993.

GUEDERT, et alli. Utilizaçāo da cinza da casca de arroz como material pozolânico adicionado a cimento portland para obtençāo de aglomerantes alternativos. In: Anais do II Simposio de desempenho de materiais e componentes de Construção Civit. Florianópolis Set. 1989. Pag. 152 a 170.
LIMA,Helder. Registro da época. In: Construçào Nortel Nordeste $n^{\circ} 255$ agosto 94 .

MAIA, Maria Aridenise Macena. Resíduo de Construção. In: Revista Tecnologia, No 14, P 68-80, Fortaleza- Dez 1993.

NOLASCO, Adriana M; AGNESINI, Marcos V.C. Utilização de Resíduos na Indústria de papel na produçāo de materiais para a construçāo civil. In: Encontro Nacional de Tecnologia do Ambiente. Construído: Avanços em tecnologia e gestão da produção de edificaçōes. Sảo Paulo, 1993.

SILVA, Maristela et alli. Proposta para Reaproveitamento de Resíduos Industriais da Regiāo da Grande Vitória em componentes de Construçäo Civil. In: Encontro Nacional de Tecnologia do Ambiente. Construido: Avanços em tecnologia e gestāo da produção de edificações. São Paulo, 1993.

SILVA, Maria A.C. et alli. Metodologia para Seleção de Sistemas Construtivos inovadores: aplicação prática no Núcleo Experimental do Municipio de Cubatão. In: Encontro Nacional de Tecnologia do Ambiente. Construído: Avanços em tecnologia e gestão da produção de edificaçōes. São Paulo, 1993. 